\title{
RE-ENGINEERING MARKETING (RM)
}

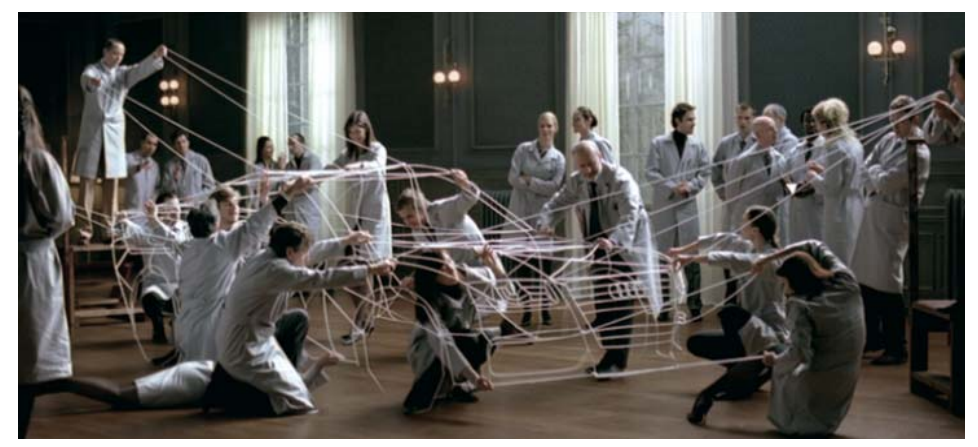

Pecvnia, Monográfico (2010), pp. 45-51

Bozhidar Iv. Hadzhiev1 cei@abv.bg University of Food Technologies

(Bulgaria)

\section{Resumen}

La globalización, el auge de la economía, el progreso de la e-net economía, y el gran dinamismo de las relaciones comerciales se están constituyendo como una función progresiva en constante crecimiento, predeterminando la utilización de unas pocas nuevas oportunidades para aumentar la eficacia de las empresas. Llegados a este punto, a través del prisma de los métodos de reingeniería en el presente artículo se muestran algunos problemas básicos y las oportunidades existentes para la Reingeniería del Marketing (RM).

Palabras clave: Re-ingeniería del marketing; teoría del marketing; nuevos modelos y desarrollos.

\section{Abstract}

Globalization, the rise of the economy, the progress of the e-net economy, and the high dynamics of business relationships are developing as one of the permanently rising progressive functions, predetermining the use of a few new opportunities for increasing effectiveness of the industry companies. At this point, through the prism of Re-engineering methods, a few basic problems and opportunities for Re-engineering Marketing (RM) are presented in this paper.

Keywords Re-engineering marketing; marketing theory; new models and developments.

1 University of Food Technologies, 26 Maritza Boulevard, Plodiv-4002 (Bulgaria). 
More and more often in the conversation with the representative of the business and academic fields I come across with the allegation that marketing theory is in crisis and marketing itself is perceived as non-effective inspite of its inconsiderable activity. In support of this statement the following facts are pointed: when the budget of a business organization is in crisis, marketing is the first thing that the budget cuts down; the percentage of failures compared to achievements are growing in a geometric progression; the count of the promotions materially decrees which lead to a result not higher than around 3\%; the digital technology changed the market, and market itself is already super fragmented; the count of the competitors is decreasing drastic according to the count of the marks and categories; the vital cycle of the products is highly decreasing.

With the present paper I whis to show that marketing is as a serious economic science as the business itself and presume united professional managing efforts in practice and theory to get the positive result from the sales. The facts mentioned above are real, but they can be different, if they are rationalized and applied the real possibilities of the marketing marked trough the conception of the Reengineering marketing.

Some contemporary scientists and business specialists as Peters and Waterman (1982), Collins and Porras (1994) or Zyman (2000), see the managing efforts for marketing as role models or following the best practice (benchmarketing).

Others, as Trout (2001), reject role models and support learning from failures and mistakes. In their opinion marketing is more to be as an engagement of a perception, and not ever related to "the better products". Even though that their statements are exaggerated, in a number of relations they are at one axis of the marketing science extracted from the experience.

Other axis of marketing science touches the technologies and theoretical methodological approach. One part of the theorists believe that marketing is shown through processes for modulate in a certain market definition of the market (need, people, situation, product), segmentation and positioning. This is the traditional marketing (Ries and Ries, 2005), which is bound by the gradual change. The mental process in it is consistent and logical from the generally to the concretization. Other theorists believe that the managing efforts in the marketing are priority connected with restructure of the markets, through creating of new categories, through innovations derive out of certain market or category (untraditional marketing) bind with divergence, disruption. With a little bit more of a risk, creativity and possibilities, the logical process takes its source from the specify to the generally.

Even so with specific exaggerated understandings, in its own nature, the efficacy of the activity in these two axles grew cold. This happens, because the system is missing, which to unite the indicated opinion and to engage the marketing option with the motivation, with the science researching activities, with the publics and with the production option. With the Re-engineering Marketing (RM) an attempt is made to reveal this system, which to integrate the different marketing theories and to mould the way for one integral marketing theory, adequate to current business. The practice reveals that RM has a number of problems 
connected with its rationalization (because of the intricacy of the complex marketing), but it gives a series of possibilities for increase efficiency of the companies.

The expose matter is very dynamic, debatable and complex. Therefore the aim is with a comprehensible and simple language of some accents trough the prim of Re-engineering method of approach the manager to be helped to get beneficial knowledge for the organization and management of marketing activity as an integral combination of strategies, communications, reviews and business transactions.

\section{Expose}

Nowadays business is considered as a market of more and more growing consumer and industrial democracy. This kind of market is a function of globalization and it previously depended on the directions of the open economics. The results from the theory of the complex Re-engineering bring to light that this direction affects a new era of technology, liberalization processes, changes in human values and more and more dynamic and diverse changes in market categories and brands $^{2}$. There is no doubt that expedience and efficiency of the above mentioned interrelationship comprise the process of establishment, reestablishment and

2 As already stated sine years ago by the autor when lecturing his students on "reasonable management practices" (2000). This previous experience provided theoretical basis for a later short course on Reengineering marketing according to current reality of economy ("Short Course on Theoretical Basis of Management", sheets 207-218 and 264-275). development of current business, but this enforce deeper research of these processes.

RM is equivalent to the achievement of the theory for the reasonable marketing Re-engineering, as we have in mind the above mentioned interrelationship of current business, as well as the mechanism for integration of the inner and outer processes of the organization. RM, as a system, first gives the opportunity to define the resources and valuables of the subject, according to these to find the suitably situation, to definite the most appropriate marketing direction (one of the four utmost understandings mentioned in the introduction), after that to derive the topical and answerable problem (aim), which to be resolved trough the efficiently strategies, communications, discussions and trades. The strategies, communications, discussions and trades are innate for each marketing trend, and they are the unitive thread in Marketing science. That is why the RM is equal to this unitive thread and it builds itself as an integral aggregation from an effective business strategies, business communications, business discussions and trades (Fig. 1).

The studies in organization with assorted business that were made prove the thesis that by applying the RM, the expedience and efficiency of business processes is growing and the business surroundings are improving considerably.

It appears that RM, in which basis are the strategies, is with much more significance than the other known marketing politics and with the time this significance is growing. 


\section{Figure 1}

\section{System of integral marketing interrelationship}

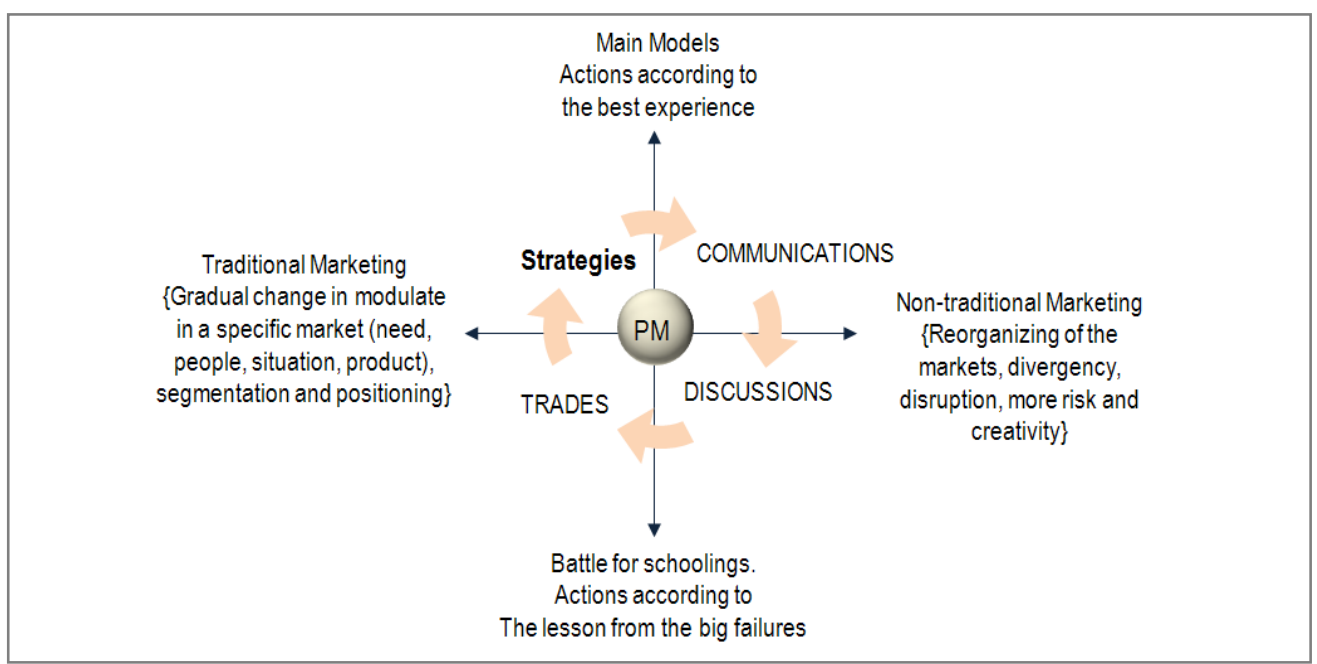

The philosophy of RM in which the studies were made can be shown through the following scheme (Fig. 2).

\section{Figure 2}

\section{Phylosophy of RM}

\section{THE PHILOSAPHY OF RM}

Potential of the company + Potential of the situation in which its lodge

$=$ The valuable system +Style of system + Style of behavior +style of action

Choice of situation according to valuable system of the company (the people of the company), vision, mission, aims, tasks

Define and redefine of the situation and action for improving of basic indicators

Result, positive change
Renationalize of the beliefs according to the needs, Form of the hypothesis, motivation and mechanism for its fulfill
Riddle of the ideas, strategies (problems) considering solution, acceptability, rationality, market chance, possibility, resource, security, profitability to the risk, feasibility
Integrating the company potential with the potential of the situation

Brain attack for forming the ideas and strategies, considering valuable conceptions, qualities, skills, ability, needs and potential of the situation considering the natural way that things are flowing and the estimate of the danger.

\begin{tabular}{|c|c|}
\begin{tabular}{c|c} 
RM-Complex Re- \\
engineering+ \\
real estimate of \\
the existing and \\
upcoming danger
\end{tabular} & $\begin{array}{c}\text { Renationalize, } \\
\text { redesign and improve } \\
\text { of the strategies and } \\
\text { processes trough real } \\
\text { judgment of existing } \\
\text { and upcoming danger }\end{array}$ \\
\hline
\end{tabular}

Engineering of the existing business (strategies, communications discussions, and trades
Engineering of future business (strategies, communication, discussion and trades
Improving of the basic indicators and the activity considering aassessment of danger 
Why RM shows as an especial useful complex Re-engineering for solving business problems and substantially elaborate the theory of reasonable management? With the theory of the Complex Re-engineering (CR) is made a try to combine the efforts over the reasonable management of the processes. Trough this theory it is understood that everything in this world is an energy (material) and information, which through the management assume one or other apartness (see Fig. 3).

Through CR theory the technology of effective alignment of the processes in one business system was revealed, as well that the main machine for developing and progress of the humanity civilization is nothing else but the constructive, creative -enterprising spirit and potential of the people around the world. Aiming getting a positive result methodology was developed and develops- for the complex Re-engineering as integration of the achievements of the economy, psychology, information and mathematics. But it appears that all this is not enough useful because of the fact that the technology can be used with the same stamina as a creative, or uncreative force, as well as due to the fact that in life the business is develop not only on allowable and professional actions. There is the need from RM.

\section{Figure 3}

\section{Interrelationships of the three basic elements of CR}

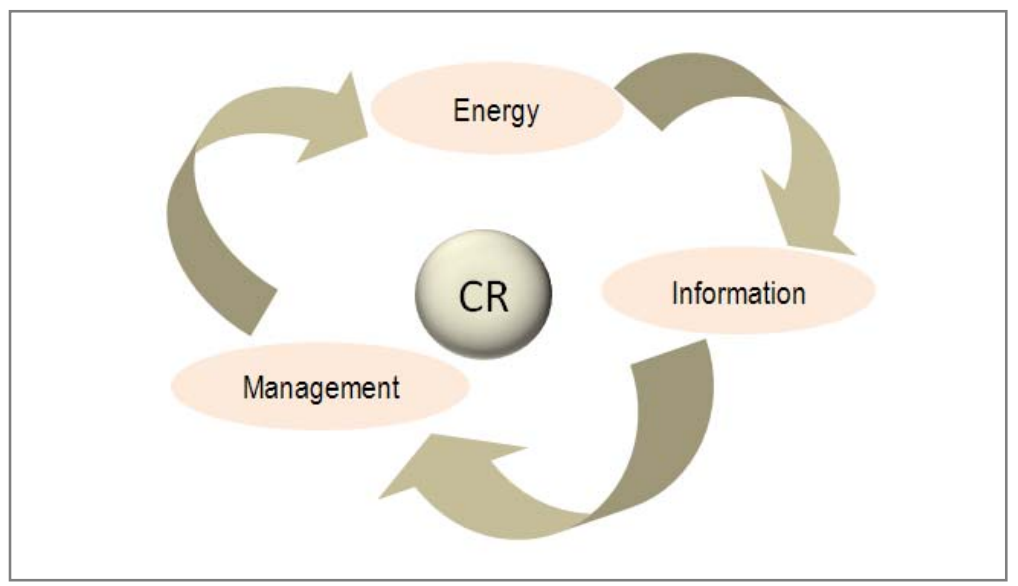

Nowadays we are in a new world, the most difficult that honest marketing professionals and businessmen have ever faced. A world where the traditional knowledge is important but it is not enough. A world where everyone teaches strategies for success with the dominant which the personal interest for everybody is to do the best only for themselves with the leading principle" power, money, money and only money". The individual wants more and more from the surroundings and less from himself although the freedom, as the great Bulgarian Ilia Beshkov says is "to load yourself more than the others". There is a question that 
arises, how efficiently to contrast on the aggressive business strategies, where the basic principals are: "The winners are not judged ", "The deceptions and modeling the reality, which do not exist", "The aim excuses the resources", "All of you are enemies", "Not the professionalize but the falsity, the falseness, the intrigues are important", "The main thing is to get the power and the resources in you hands and the morality, the spirituality and the morals do not exist they are only for the punks" and etc.

Obviously the reasonable management (reengineering) of the processes is important, but this is not enough for the business with this kind of strategies to manage it. In every other moment the strategies interact itself with different power and range. A lot of the strategies are chain reaction from a certain global strategy. Often those who work on settled sub-strategies think that they are the only

one and unique and difficult define the situation and often they do not survive. To survive under the pressure each organization reacts with specific strategies for structure and company management apparatus, for manufacture and commerce, for the technologies, recourses, communication and trades. The strategy can be well-timed and adequate, the recourses can be enough, but if the strategies of the competitor are dishonest or the risk is misjudged the chance of being razed is obvious.

In RM the point is a real estimation for the exciting and upcoming danger. For the success the management knowledge and actions, the necessary recourses and information are not enough, we require the indispensable time for accomplishment of each strategy. That is why if we do not assure the right duration, the race is obvious. This proves that even the most reasonable and competent manager can not always be almighty. He is forceless when the right management knowledge is missing (for right determination of the strategy, for efficient business communication, discussion and trades when accomplishing this strategy), the recourses, the necessary time and information for a real estimation of the danger.

RM comprehends the determination of the anterior strategies, business communications, discussions and trades, the mentally test of the situations and the checkup in practice. This election integrates all other options in the business organization (marketing, production, finances, internal and among company relationships and hence) and affects the business as whole, but in a biggest extent it affects the management efforts (ME), which determinates the direction (the choice) for creation, development and recreation of one or another business system. These effortsp, in their own nature, are the "expenses" taking shape in as a relation of the advantage $(A)$ to the values $(V)$. The nowadays this is the expenses taking shape in money, which we pay, the time we devote ,the risks which we stand with the management decisions and the maintenances and organization expenses in the suitably action and its production. Notedly from Fig. 3 these efforts are function of consuming in the energy system (E) and the level of information (I) and all this can be present the following way:

(1) $M E=f(E, I)=A N$,

After the results from the research that was made in the organizations with assorted business trough the formula the following conclusions has been made:

- As much energy the system consume as much the management marketing efforts increase and the needed information decreases

- When the basis information in a business system increases and gets wide 
accessible, then the efforts and resources increase for marketing activity.

- The growth of the information and the speed it runs the processes in one business system leads to sensation for faster run of the time (time shrinkage).

- In a stable advantage for the organization "the business machine" must work with less energy and information. Of course we have to have in mind that when the energy for the system decreases, the information increases and the opposite. So for smaller management marketing efforts with the same information is normal that the information of the business system energy to decrease.

- At present the main problem is not the information, but its accessibility, quantity and contents (Less then ten years ago, whoever had the information succeeded. In these days there is all kind of information). The problem is not to make a good advertising, demonstration, a good marketing mix which to gets all kind of prizes and to be liked by the owner

- And the crowd but the fundamental problem is the management of the information, where the business to be point at, what kind of strategy to be chosen, how to manage this strategy, how to communicate and negotiate so the profit from the sales and retrievals of each investment for marketing action can be stably increase.

As we see from the above mentioned RM gets to be more necessary for the business and its management and organization transform in a wonderful adventure.

\section{References}

Collins, J.C. and Porras, J.I. (1994). Build to last: successful habits of visionary companies. New York: Harper Business.

Peters, T.J. and Waterman, R.H. (1982). In search of the excellence. Lessons from America's best-run companies. New York: Harper\&Row.

Ries, A. and Ries, L. (2005). The origin of brands. New York: Collins.

Trout, J. (2001). Big brands. Big trouble: lessons learned the hard way. New York: John Wiley \& Sons.

Zyman, S. (2000). The end of marketing as we know it. New York: Haper Collins.

\section{Images}

Page 45: http://www.controlpublicidad.com/control/noticias/quiero-profundizaren/informes-y-estudios/tns-augura-menos-publicidad-de-coches-en-2009. 